\title{
The Universality of the Portrayal of Gender in Television Advertisements: An East-West Comparison
}

\author{
Grace Lim¹, Adrian Furnham,2 \\ ${ }^{1}$ Research Department of Clinical, Educational and Health Psychology, University College London, London, UK \\ ${ }^{2}$ Norwegian Business School (BI), Nydalveien, Olso, Norway \\ Email: a.furnham@ucl.ac.uk
}

How to cite this paper: Lim, G., \& Furnham, A. (2016). The Universality of the Portrayal of Gender in Television Advertisements: An East-West Comparison. Psycho$\log$, 7, 1608-1623.

http://dx.doi.org/10.4236/psych.2016.713154

Received: October 8, 2016

Accepted: November 11, 2016

Published: November 14, 2016

Copyright $\odot 2016$ by authors and Scientific Research Publishing Inc. This work is licensed under the Creative Commons Attribution International License (CC BY 4.0).

http://creativecommons.org/licenses/by/4.0/ (c) (i) Open Access

\begin{abstract}
This study compared portrayals of gender in Malaysian and British television advertisements regarding the portrayal of men and women across these two countries. A total of 236 advertisements were content analyzed for nine variables relating to the primary character of the advertisement. The findings provide evidence of gender stereotyping in both countries for types of products advertised, credibility and role of the primary characters. The results suggest that portrayals in British advertisements are similar to those in Malaysian advertisements despite the cultural gap. These findings are discussed in relation to implications and the limitations of the study are noted.
\end{abstract}

\section{Keywords}

Television Advertisements, Gender Role, Malaysia, Great Britain, Product Type, Expertise, Location, Credibility

\section{Introduction}

This study examines differences in gender portrayal in television advertisements between the predominantly Christian, Western, United Kingdom and the overwhelmingly Muslim, Eastern Malaysia through content analysis.

There is an extensive and ever growing literature on sex stereotyping and gender role portrayal in advertising (Kay \& Furnham, 2013; Knoll, Eisend, \& Steinhagen, 2011). Indeed there are now well over 100 studies that have investigated gender portrayal in national television advertising (Furnham \& Mak, 1999; Furnham \& Paltzer, 2010; Furnham \& Lay, 2017). Moreover a recent review considered gender-role advertising in 
international advertising (Shaw, Eisend, \& Tan, 2014).

However, Eisend (2010) pointed out that prior research predominately examined short-term attitude changes. His meta-analysis of 64 studies regarding gender portrayal in advertising found that advertising primarily depended on the widely accepted gender attitudes and values in a society with no significant lasting effects on viewer's attitudes. This study has been the first to provide definitive evidence to the debate regarding the influence of advertising on perception of gender roles in society. This corroborates the assumptions of earlier researchers regarding how stereotyped advertisements were simply "lagging social indicators", i.e. the media perpetuating outdated perceptions which are no longer aligned with the current state of society rather than attempts to impose gender role beliefs.

Although gender stereotyped advertisements appeal to more traditional people, Morrison and Shaffer (2003) found that traditional individuals viewed non-conventional advertisements more favourably when prompted to self-reference. Additionally, researchers such as Caballero, Lumpkin and Madden (1989) also noted that stereotypical images may possibly dissuade consumers; this is potentially due to these perceptions being viewed as outdated and perhaps offensive by more progressive individuals. In combination with the progress of gender equality, it may be in the interests of advertisers to rely on less stereotypical advertising particularly when the advertisements attempt to relate to the consumer.

Women tended to be used to advertise home and body products while services, technological and automotive products were primarily advertised by men (Furnham \& Bitar, 1993; Furnham \& Mak, 1999; Bresnahan, Inoue, Liu, \& Nishida, 2001; Uray \& Burna, 2003). However, there appeared to be mixed results for food advertising, e.g. between Malaysia and Japan. The most surprising findings were that of Tan, Ling and Theng (2002) as Singaporean advertisements favoured women for phone and computer commercials in comparison while its South-east Asian neighbour, Malaysia, used men in the majority of telecommunications commercials. This may be a significant example of how role perception in South East Asia may be changing with increased Westernization and concepts of gender equality being more commonplace. Based on the findings of previous studies, it is predicted that females would be more likely associated with home and body products than males in both Malaysia and Britain.

Coinciding with the association between women and home products, female primary characters tended to be portrayed as being at home while men were more likely to be shown outdoors (Bretl \& Cantor, 1988; Gilly, 1988; Furnham \& Bitar, 1993; Uray \& Burnaz, 2003; Furnham \& Mak, 1999). Furnham and Paltzer (2010) noted, in a metaanalysis of 30 studies performed in this area in the last decade, that the level of stereotyping in regard to location was lower in countries such as Kenya and New Zealand though women were still far more likely to be pictured at home in Mauritius, the United States and Malaysia. Bresnahan et al. (2001) observed that Malaysian men were overall more likely to be portrayed in the workplace as expected of a country with a patriarchal society. There were no significant differences found for British, Mexican and 
French advertisements in a meta-analysis conducted on 14 studies across 11 countries (Furnham \& Mak, 1999). On the other hand, females were portrayed far more frequently at home while men were more likely to be depicted in occupational settings in other studies of British advertisements (Furnham \& Bitar, 1993; Furnham \& Paltzer, 2010). Therefore, it is hypothesised that both Malaysian and British female primary characters would be more likely to be depicted at home than males.

The tendency to portray males as an authority with expertise while relegating women to the role of users and models appeared to be sustained across time in Britain (Manstead \& McCulloch, 1981; Furnham \& Mak, 1999; Uray \& Burnaz, 2003; Furnham \& Paltzer, 2010). However, Bretl and Cantor (1988) have noted an increasing number of males in the "user" role thereby suggesting that the media may be slowly acknowledging changes in the status quo and reflecting it in their advertising. This study will explore the credibility associated with men and women in Malaysia as research performed in the last decade regarding Malaysian commercials (Bresnahan et al., 2001; Tan et al., 2002) had neglected this category. Due to the persistent stereotypical depictions found in prior studies, it is predicted that men would be portrayed as authorities while women would be portrayed as users in both countries.

The research regarding credibility coincides with the way that men tend to consistently be portrayed as employed professionals in autonomous while women tend to be unemployed or familial roles in countries ranging from the US to Japan to Mauritius (Gilly, 1988; Bresnahan et al., 2001; Uray \& Burnaz, 2003; Kim \& Lowry, 2005; Furnham \& Paltzer, 2010). British advertisements tended to portray men in autonomous roles and women in dependent roles even though an increasing percentage of women have been depicted in the role of interviewers (Manstead \& McCulloch, 1981; Furnham \& Skae, 2015). Tan et al. (2002) found that males were still more likely to be portrayed in professional roles than females in Malaysia and thus significant gender stereotyping is still expected for Malaysia; as with the UK based on the aforementioned studies. On the other hand, Bretl \& Cantor (1988) and Furnham \& Mak (1999) found no significant evidence for role stereotyping but that has been attributed due to low sample sizes and high number of role categories. It is hypothesised that Malaysian and British female primary characters will be more likely to be depicted in non-occupational roles.

There were generally two types of arguments used in prior studies: factual and opinion based. Furnham and Mak (1999) and Furnham and Paltzer (2010) found that men primarily gave factual arguments for a product in a majority of the samples while women tended to give opinions (e.g. Serbia, Italy, Portugal and Indonesia) or a relatively even mix of opinion-based and factual based arguments (e.g. Hong Kong and Japan). Although Australian advertisements were generally found to be less stereotypical (Gilly, 1988), a majority of commercials used opinion based arguments with females primarily not making an argument (Furnham \& Paltzer, 2010). This could signify that a reversal is occurring in less traditional countries whereby opinions are preferred to factual arguments as marketing companies attempt to make their products feel more relevant to the consumer through anecdotal evidence. 
Furnham \& Mak (1999) observed that female characters in British commercials were more likely to make factual arguments in comparison to male characters; this could possibly be in order to appeal to more female consumers since the advent of gender equality movements. Therefore, it is hypothesised that British female primary characters will be depicted using factual arguments more frequently than males. It is also hypothesised that females will tend to be shown using opinion-based arguments while males are shown use factual arguments in Malaysian advertisements due to the traditional nature of the country wherein women are viewed as being less knowledgeable than men.

There was a noticeable difference the type of rewards marketed with the general trend being pleasurable rewards for men who use the product and self-improvement as motivators for women in the UK as well as multiple other countries (Manstead \& McCulloch, 1981; Furnham \& Mak, 1999; Furnham \& Skae, 2015; Furnham \& Paltzer, 2010). However, there appears to be a mixed result regarding the use of practicality as a motivator. There was also within country differences found (Furnham \& Paltzer, 2010) in Hong Kong whereby the usage of practicality as a reward increased when the advertisement was in Chinese instead of English. There is a possibility that advertisements in the native tongue of the country are more reflective of their current standards than those in a foreign language as those who are multilingual (and thus more likely to be exposed to foreign cultures) may be more receptive to unconventional gender portrayals. Therefore, this study will focus mainly on advertisements produced in Malaysia and those which use Bahasa Melayu to obtain more accurate information regarding gender role portrayals within the country. It is predicted that female primary characters would be more likely to promote products based on practicality and self-enhancement and that males would use pleasure in both Malaysian and British advertisements.

There has been little research done regarding the temperament of the primary characters in television advertising. Gilly (1988) observed that Mexican women were more likely to be portrayed as frustrated while this was true for men in Turkish advertisements (Uray \& Burnaz, 2003). As frustration is one of the affective by-products of helplessness (Seligman, 1975), women may be more likely to be depicted as frustrated in more traditional cultures wherein women are viewed as being less autonomous and capable than men. Thus, it is predicted that Malaysian female primary characters will be significantly more frustrated than the males while no gender differences are expected for frustration in British advertisements.

Similarly, few studies have incorporated humour as a factor despite the efficacy of humour in advertising (Furnham, Gunter, \& Walsh, 1998). Furnham and Skae (2015) posited that sex-role reversals may occur mainly in humorous circumstances, e.g. the inept male in a homemaker role rather than a serious depiction of non-traditional roles. This study will explore the general usage of humour in British and Malaysian advertising with the prediction that "humour" will be utilized more frequently in the presence of "role reversals".

Finally, the bulk of prior research in this area has neglected the degree of sexualisa- 
tion in televised advertising. Past studies (Gilly, 1988; Furnham \& Mak, 1999; Furnham \& Paltzer, 2010) have shown that female primary characters have been consistently younger than males even across cultures and the decades since the original study. Although earlier studies had initially found that a greater proportion of married female primary characters (Schneider \& Schneider, 1979; Cagli \& Durukan, 1989), a recent study by Kim and Lowry (2005) noticed that women tended to be shown as unmarried in an analysis of Korean adverts. This may indicate an increasing use of sex appeal and a decreasing focus on the importance of social hierarchy whereby women were traditionally perceived as being more "respectable" due to their married status. Thus, this study aims to explore the levels of sexualisation of primary characters in a conservative, religious country (Malaysia) with a more sexually tolerant, secular country (UK). Earlier studies regarding television and magazine advertising conducted in the US (Lin, 1998; Sullivan \& O' Conner, 1988) would indicate that women are more likely to be sexualised than men while Ingrassia (1994) has observed that males have also been increasingly portrayed in this manner. This study predicts that females would be more likely to be sexualised in both Malaysian and British advertisements.

Furnham and Mak (1999) noted that gender role stereotyping was more prevalent in more traditional countries such as Indonesia and Hong Kong even exceeding the levels found in the United States in the original studies from the 1970's. They argued that the high levels of stereotyping found in Asian countries such as Indonesia may be due to the relatively late introduction of technological advances in comparison to more developed countries. As media technology facilitates the spread of new ideas, the "cultural lag" (Cooper-Chen, 1995) regarding gender equality may have been influenced by the later introduction of television. Therefore, it is possible that there has been more progression in terms of gender role perception and greater acceptance of unconventional gender roles in the country since prior studies.

This study expects findings from the Malaysian sample to be similar to those of in Turkey (Uray \& Burnaz, 2003) and Hong Kong (Furnham \& Li; 2008), i.e. a significant gender gap though with more equal proportions of males and females distributed within the variables; due to a shift from collectivist to individualistic systems of thought as a result of increased Westernization. Malaysia is an Islamic country which adheres highly to traditional Malay culture with Islam being a strong foundation for many of the cultural norms and laws. A census conducted by the CIA in 2000 had found that $60.4 \%$ of the population were Muslim, 19.2\% were Buddhist, $9.1 \%$ were Christian, $10.4 \%$ followed other religions while only $0.8 \%$ surveyed had no religion. It has also been noted that there has been strong gender stereotyping and linguistic sexism in Malaysian textbooks such as associating fathers with decision-making authorities with financial and occupational responsibilities while mothers were associated with childcare, cooking and cleaning the house (Hamid, Yasin, Bakar, Chee, \& Jaludin, 2008). This is in contrast to the United Kingdom where around 15\% of those surveyed in a 2001 government census conducted stated that they had no religion; the predominant religion was Chrisitanity (71.6\%). 
Women comprised of only around 35\% of Malaysia's labour force from 1975 to 2002, with small variations depending on work sectors. Furthermore, only about $10 \%$ of Malaysia's Parliamentary members and $6.3 \%$ of the elected State Legislative Assembly consisted of females even in 2004. The drastic under representation of women both in the workforce and politically would impede the progression towards a culture of gender equality in Malaysia. On the other hand, women had already made up 65\% of those employed in the public sector and $41 \%$ of those in private sectors in the UK by 2004 . This would mean that, despite the lack of gender balance in employment for both countries, Malaysia is lagging behind the UK in terms of promoting professional career options for women while reinforcing stereotypical gender roles.

This template, created in MS Word 2007, provides authors with most of the formatting specifications needed for preparing electronic versions of their papers. All standard paper components have been specified for three reasons: 1) ease of use when formatting individual papers, 2) automatic compliance to electronic requirements that facilitate the concurrent or later production of electronic products, and 3) conformity of style throughout a journal paper. Margins, column widths, line spacing, and type styles are built-in; examples of the type styles are provided throughout this document and are identified in italic type, within parentheses, following the example. Some components, such as multi-leveled equations, graphics, and tables are not prescribed, although the various table text styles are provided. The formatter will need to create these components, incorporating the applicable criteria that follow.

\section{Method}

\subsection{Sample}

The sample of advertisements analysed in this study were obtained by recording primetime television programming in three hour slots (19:00-22:00) during Monday to Fridays for a span of two weeks. The Malaysian sample consisted of advertisements aired on TV3 and Astro Ria during the weeks of $7^{\text {th }}$ September and $14^{\text {th }}$ September 2009 . The British sample consisted of recordings from ITV and Channel 4 for the weeks of $9^{\text {th }}$ November and $16^{\text {th }}$ November 2009. Similar to Bretl and Cantor (1988) and Craig (1992), all public service announcements, programming related advertisements and duplicates were excluded from the final samples. Purely narrative advertisements, those containing more than one primary character and those solely containing gender neutral animated characters were also removed. 136 Malaysian advertisements and 100 British advertisements were obtained for the final samples.

\subsection{Coding Procedure}

Following Bretl and Cantor (1988), an individual coded the entirety of the samples based on the criteria listed below and a second individual coded a random subset of 33 advertisements. Both coders were bilingual and the second coder was an independent party unaware of the experimental hypotheses of the study. Inter-coder reliability was found to be at $81.5 \%$ with agreements on 242 out of 297 coded items. 


\subsection{Coding Criteria}

Primary characters were coded based on gender and defined as characters with the most screen-time and/or dialogue during the advertisement (McArthur \& Resko, 1975; Schneider \& Schneider, 1979; Bretl \& Cantor, 1988; Tan et al., 2002). In advertisements where there were multiple characters, the more prominent was selected as the primary character (Uray \& Burnaz, 2003). The advertisements were further coded according to nine other variables relating to the general attributes of the advertisement and the attributes of the primary character. The variables chosen were based on those frequently used by prior content analyses but some categories have been altered or collapsed to accommodate for the smaller sample sizes in this study. The definitions of these variables and their sources are listed in Table 1 and Table 2.

\section{Results}

Chi-square tests were performed comparing the frequency distributions for male and female primary characters for UK and Malaysian advertisements. Cross-cultural comparisons were also performed, i.e. comparing depictions of one gender in the UK with depictions of the same gender in Malaysia. In the few cases where none of the options were suitable (e.g. role was not applicable as the primary character was only seen from the neck up) or fit more than one option in the category (e.g. more than one type of reward was presented), they were excluded from the statistical analysis (Table 3 ).

Hypothesis 1: Product Types. In regard to British advertisements, females were more likely advertise health and beauty products than males $(43.1 \%$ vs. $17.0 \%)$ and were also more likely to advertise household products ( $12.1 \%$ vs. $2.8 \%)$. Male characters tended to advertise services more frequently than female characters (23.8\% vs. $3.4 \%)$. Similarly, women in Malaysia were more likely to be shown promoting health and beauty products $(52.6 \%)$ in comparison to men $(25.6 \%)$ while men were more likely to be shown advertising food products $(53.8 \%$ vs. $18.6 \%)$. Significant gender differences were found for both the $\mathrm{UK}\left(\mathrm{X}^{2}=18.08, \mathrm{df}=5, p<0.005\right)$ and Malaysia $\left(\mathrm{X}^{2}=18.27, \mathrm{df}=\right.$ $5, p<0.005)$ therefore the hypothesis that females would be more likely to promote home and body products than males in both countries was supported.

Table 1. Variables related to the attributes of the advertisement.

\begin{tabular}{ccc}
\hline Variable & Operational definition & Basis of categories used \\
\hline $\begin{array}{c}\text { Gender of } \\
\text { primary } \\
\text { character }\end{array}$ & $\begin{array}{c}\text { Is the primary character: } \\
\text { 1. Male, 2. Female }\end{array}$ & $\begin{array}{c}\text { McArthur \& Resko (1975) } \\
\text { Bretl \& Cantor (1988) } \\
\text { Tan et al. (2002) }\end{array}$ \\
Product type & $\begin{array}{c}\text { What type of product is being advertised? } \\
\text { 1. Food, 2. Health and Cosmetic, 3. Electronics, } \\
\text { 4. Services, 5. Household, 6. Other products }\end{array}$ & $\begin{array}{c}\text { Modified version of } \\
\text { Schneider \& Schneider (1979) }\end{array}$ \\
& Where is the location of the character? & Modified version of \\
Location & 1. Home, 2. Outside, 3. Non-specific & Bretl \& Cantor (1988) \\
& & Furnham \& Mak (1999)
\end{tabular}


Table 2. Variables related to the primary characters.

\begin{tabular}{|c|c|c|}
\hline Variables & Operational definition & Basis of categories used \\
\hline Credibility & $\begin{array}{c}\text { The character is credible because s/he is } \\
\text { portrayed as the: } \\
\text { 1. Authority, } 2 \text {. User }\end{array}$ & Furnham \& Bitar (1993) \\
\hline Role & $\begin{array}{l}\text { What is the role/occupation of the character: } \\
\text { 1. Professional, 2. Non-professional }\end{array}$ & $\begin{array}{l}\text { Modified version of } \\
\text { Tan et al. (2002) }\end{array}$ \\
\hline Arguments & $\begin{array}{l}\text { What is the basis of the argument used? } \\
\text { 1. Facts, } 2 \text {. Opinions, } 3 \text {. None }\end{array}$ & Furnham \& Bitar (1993) \\
\hline Rewards & $\begin{array}{l}\text { What rewards are offered to users of the product? } \\
\text { 1. Practical, 2. Self-improvement, 3. Pleasure, } 4 . \\
\text { None given }\end{array}$ & $\begin{array}{l}\text { Furnham \& Bitar (1993) } \\
\text { Furnham \& Paltzer (2010) }\end{array}$ \\
\hline Frustration & $\begin{array}{c}\text { Does the character show any frustration? } \\
1 \text {. Yes, } 2 \text {. No }\end{array}$ & Gilly (1988) \\
\hline Humour & 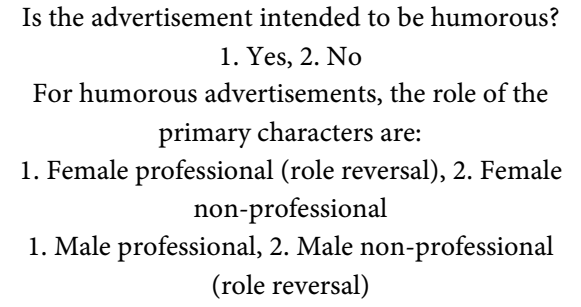 & $\begin{array}{l}\text { Modified version of } \\
\text { Bretl \& Cantor (1988) }\end{array}$ \\
\hline Sexualisation & $\begin{array}{c}\text { Is the character portrayed as an object of } \\
\text { sexual/physical attraction? } \\
\text { 1. Yes, } 2 \text {. No }\end{array}$ & \\
\hline
\end{tabular}

Hypothesis 2: Credibility. For both countries, males were more frequently shown as authorities (UK: $31.6 \%$, Malaysia: $38.5 \%$ ) while females were more frequently shown as users (UK: $90.4 \%$, Malaysia: $83.5 \%),\left(\mathrm{X}^{2}\right)_{\mathrm{UK}}=6.91 \mathrm{df}=1, p<0.01$ and $\left(\mathrm{X}^{2}\right)_{\text {Malaysia }}=6.43$, $\mathrm{df}=1, p<0.01$. Therefore, this supports the hypothesis that males would be more likely to be depicted as authorities and females as users in advertisements.

Hypothesis 3: Roles. British male primary characters were depicted almost equally in professional (44.7\%) and non-professional occupations (55.4\%) while female characters were far more often shown as non-professionals (89.3\%), $\mathrm{X}^{2}=14.18 \mathrm{df}=1, p<$ 0.001 . A comparable trend was also found in Malaysian advertisements whereby men were shown almost equally as professional and non-professional ( $43.2 \%$ vs. $56.8 \%)$ while $15 \%$ of women were shown in professional roles, $\mathrm{X}^{2}=11.85, \mathrm{df}=1, p=0.001$. This supports the hypothesis that females would be more likely to be depicted in non-professional roles in both Malaysian advertisements and British advertisements

Hypothesis 4: Location. There were no statistically significant gender differences found in location of the primary character for both the $\mathrm{UK}\left(\mathrm{X}^{2}=5.28, \mathrm{df}=2, p>0.05\right)$ and Malaysia $\left(\mathrm{X}^{2}=5.92, \mathrm{df}=2, p=0.052\right)$; although the Malaysian sample was close to significant with $23.7 \%$ more males being portrayed outside.

Hypothesis 5: Arguments. Hypothesis 5a: There was no significant gender difference found in the type of arguments used in Malaysian advertisements, $\mathrm{X}^{2}=1.83 \mathrm{df}=$ 
Table 3. Comparisons of characteristics related to male and female characters in British and Malaysian commercials.

\begin{tabular}{|c|c|c|c|c|}
\hline & \multicolumn{2}{|c|}{ UK } & \multicolumn{2}{|c|}{ Malaysia } \\
\hline & Male (\%) & Female (\%) & Male (\%) & Female (\%) \\
\hline \multicolumn{5}{|c|}{ Product } \\
\hline & $\mathrm{N}=42$ & $\mathrm{~N}=58$ & $\mathrm{~N}=39$ & $\mathrm{~N}=97$ \\
\hline Food & $11(26.2)$ & $13(22.4)$ & $21(53.8)$ & $18(18.6)$ \\
\hline Health & $8(17.0)$ & $25(43.1)$ & $10(25.6)$ & $52(53.6)$ \\
\hline Electronic & $6(14.3)$ & $2(3.4)$ & $2(5.1)$ & $5(5.2)$ \\
\hline Services & $10(23.8)$ & $2(3.4)$ & $1(12.6)$ & $3(3.1)$ \\
\hline Househd & $2(4.8)$ & $7(12.1)$ & $4(10.3)$ & $11(11.3)$ \\
\hline Other & 5 (11.9) & $9(15.5)$ & $1(2.6)$ & $8(8.2)$ \\
\hline \multicolumn{5}{|c|}{$\left(\mathrm{X}^{2}\right)_{\mathrm{UK}}=18.08, \mathrm{df}=5, p<0.005\left(\mathrm{X}^{2}\right)_{\text {Malaysia }}=18.27, \mathrm{df}=5, p<0.005$} \\
\hline \multicolumn{5}{|c|}{ Credibility } \\
\hline & $\mathrm{N}=38(100)$ & $\mathrm{N}=52(100)$ & $\mathrm{N}=39$ & $\mathrm{~N}=95$ \\
\hline Authority & $12(31.6)$ & $5(9.6)$ & $15(38.5)$ & $17(17.9)$ \\
\hline User & $26(68.4)$ & $47(90.4)$ & $24(61.5)$ & $78(82.1)$ \\
\hline \multicolumn{5}{|c|}{$\left(\mathrm{X}^{2}\right)_{\mathrm{UK}}=6.91, \mathrm{df}=1, p<0.01\left(\mathrm{X}^{2}\right)_{\text {Malaysia }}=6.43, \mathrm{df}=1, p<0.01$} \\
\hline \multicolumn{5}{|c|}{ Role } \\
\hline & $\mathrm{N}=38(100)$ & $\mathrm{N}=56(100)$ & $\mathrm{N}=37$ & $\mathrm{~N}=93$ \\
\hline Professional & $17(44.7)$ & $6(10.7)$ & $16(43.2)$ & $14(15.1)$ \\
\hline Non-professional & $21(55.3)$ & $50(89.3)$ & $21(56.8)$ & $79(85.0)$ \\
\hline \multicolumn{5}{|c|}{$\left(\mathrm{X}^{2}\right)_{\mathrm{UK}}=14.18, \mathrm{df}=1, p<0.001\left(\mathrm{X}^{2}\right)_{\text {Malaysia }}=11.85, \mathrm{df}=1, p=0.001$} \\
\hline \multicolumn{5}{|c|}{ Location } \\
\hline & $\mathrm{N}=42$ & $\mathrm{~N}=58$ & $\mathrm{~N}=36$ & $\mathrm{~N}=97$ \\
\hline Home & $8(19.0)$ & $23(39.7)$ & $10(27.8)$ & $45(46.4)$ \\
\hline Outside & $23(54.8)$ & $21(36.2)$ & $23(63.9)$ & $39(40.2)$ \\
\hline Non-Spec & $11(26.2)$ & $14(24.1)$ & $3(8.3)$ & $13(13.4)$ \\
\hline \multicolumn{5}{|c|}{$\left(\mathrm{X}^{2}\right)_{\mathrm{UK}}=5.28, \mathrm{df}=2, p>0.05\left(\mathrm{X}^{2}\right)_{\text {Malaysia }}=5.92, \mathrm{df}=2, p=0.052$} \\
\hline \multicolumn{5}{|c|}{ Arguments } \\
\hline & $\mathrm{N}=42$ & $\mathrm{~N}=56$ & $\mathrm{~N}=39$ & $\mathrm{~N}=96$ \\
\hline Facts & $8(19.0)$ & $23(39.7)$ & $9(23.1)$ & $29(30.2)$ \\
\hline Opinions & $27(64.3)$ & $23(39.7)$ & $24(61.5)$ & $59(61.5)$ \\
\hline None used & 7 (16.7) & $10(17.2)$ & $6(15.4)$ & $8(8.3)$ \\
\hline \multicolumn{5}{|c|}{$\left(\mathrm{X}^{2}\right)_{\mathrm{UK}}=6.24, \mathrm{df}=2, p<0.05\left(\mathrm{X}^{2}\right)_{\text {Malaysia }}=1.83, \mathrm{df}=2, p>0.05$} \\
\hline \multicolumn{5}{|c|}{ Rewards } \\
\hline & $\mathrm{N}=39$ & $\mathrm{~N}=51$ & $\mathrm{~N}=34$ & $\mathrm{~N}=96$ \\
\hline Practical & $8(20.5)$ & $7(13.7)$ & $1(2.9)$ & $9(9.4)$ \\
\hline Self-impr & $7(17.9)$ & $22(43.1)$ & $11(32.4)$ & $47(49.0)$ \\
\hline Pleasure & $16(41.0)$ & $15(29.4)$ & $12(35.3)$ & $17(17.7)$ \\
\hline
\end{tabular}


Continued

\begin{tabular}{|c|c|c|c|c|}
\hline None given & $8(20.5)$ & $7(13.7)$ & $10(29.4)$ & $23(24.0)$ \\
\hline \multicolumn{5}{|c|}{$\left(\mathrm{X}^{2}\right)_{\mathrm{UK}}=6.44, \mathrm{df}=3, p>0.05\left(\mathrm{X}^{2}\right)_{\text {Malaysia }}=6.68, \mathrm{df}=3, p>0.05$} \\
\hline \multicolumn{5}{|c|}{ Frustration } \\
\hline & $\mathrm{N}=42$ & $\mathrm{~N}=58$ & $\mathrm{~N}=39$ & $\mathrm{~N}=97$ \\
\hline Yes & $4(9.5)$ & $4(6.9)$ & $1(2.6)$ & $14(14.4)$ \\
\hline No & $38(90.5)$ & $54(93.1)$ & $38(97.4)$ & $83(85.6)$ \\
\hline \multicolumn{5}{|c|}{$\left(\mathrm{X}^{2}\right)_{\mathrm{UK}}=0.23, \mathrm{df}=1, p>0.05\left(\mathrm{X}^{2}\right)_{\text {Malaysia }}=3.99, \mathrm{df}=1, p<0.05$} \\
\hline \multicolumn{5}{|c|}{ Humour } \\
\hline & $\mathrm{N}=42$ & $\mathrm{~N}=58$ & $\mathrm{~N}=39$ & $\mathrm{~N}=97$ \\
\hline Yes & $18(42.9)$ & $18(31.0)$ & $4(10.3)$ & $12(12.4)$ \\
\hline No & $24(57.1)$ & $40(69.0)$ & $35(89.7)$ & $85(87.6)$ \\
\hline \multicolumn{5}{|c|}{$\left(\mathrm{X}^{2}\right)_{\mathrm{UK}}=1.48, \mathrm{df}=1, p>0.05\left(\mathrm{X}^{2}\right)_{\text {Malaysia }}=0.12, \mathrm{df}=1, p>0.05$} \\
\hline \multicolumn{5}{|c|}{ Roles of those in humorous advertisements } \\
\hline & $\mathrm{N}=18$ & $\mathrm{~N}=18$ & $\mathrm{~N}=4$ & $\mathrm{~N}=12$ \\
\hline Profess. & $7(38.9)$ & $4(22.2)$ & $2(5.1)$ & $1(1.0)$ \\
\hline Non-prof & $11(61.1)$ & $14(77.8)$ & $2(5.1)$ & $11(11.3)$ \\
\hline \multicolumn{5}{|c|}{$\left(\mathrm{X}^{2}\right)_{\mathrm{UK}}=1.18, \mathrm{df}=1, p>0.05\left(\mathrm{X}^{2}\right)_{\text {Malaysia }}=3.42, \mathrm{df}=1^{*}$} \\
\hline \multicolumn{5}{|c|}{ Sexualisation } \\
\hline & $\mathrm{N}=42$ & $\mathrm{~N}=58$ & $\mathrm{~N}=39$ & $\mathrm{~N}=97$ \\
\hline Yes & $3(7.1)$ & $11(19.0)$ & $0(0.0)$ & $9(9.3)$ \\
\hline No & $39(93.0)$ & $47(81.0)$ & $39(100)$ & $88(90.7)$ \\
\hline \multicolumn{5}{|c|}{$\left(\mathrm{X}^{2}\right)_{\mathrm{UK}}=2.83, \mathrm{df}=1, p>0.05\left(\mathrm{X}^{2}\right)_{\text {Malaysia }}=3.88, \mathrm{df}=1, p<0.05$} \\
\hline
\end{tabular}

2, $p>0.05$, therefore the hypothesis was not supported. Hypothesis 5b: Males were more likely to use opinion based (64.3\%) rather than factual arguments $(19.0 \%)$ while females were equally likely to use either arguments, $\mathrm{X}^{2}=6.24 \mathrm{df}=2, p<0.05$. The results contradict the hypothesis that females would be more likely to use factual arguments in British advertisements.

Hypothesis 6: Rewards. No significant gender differences were found in either country for the type of rewards used by the primary character to promote the product despite a general trend for women to use self-improvement as a reward, (X2) UK $=6.44$, $\mathrm{df}=3, p>0.05,(\mathrm{X} 2)$ Malaysia $=6.68, \mathrm{df}=3, p>0.05$.

Hypothesis 7: Frustration. Hypothesis 7a: As predicted, there was no significant difference found between genders for frustration in British commercials, $\mathrm{X}^{2}=0.23 \mathrm{df}=$ $1, p>0.05$. Hypothesis $7 \mathrm{~b}$ : Females (14.4\%) were shown to be frustrated more often in Malaysian commercials in comparison to men (2.6\%), $\mathrm{X}^{2}=3.99, \mathrm{df}=1, p<0.05$.

Hypothesis 8: Humour. There was no gender difference in the presence of humour in the $\mathrm{UK}\left(\mathrm{X}^{2}=1.48 \mathrm{df}=1, p>0.05\right)$ or Malaysia $\left(\mathrm{X}^{2}=0.120, \mathrm{df}=1, p>0.05\right)$. When the sample from this category was further sorted into professional and non-professional roles, whereby a female professional and male non-professional signified role reversals 
in the advertisement, there was still a lack of significant difference in the distribution for both the UK $\left(\mathrm{X}^{2}=1.18, \mathrm{df}=1, p>0.05\right)$ and Malaysia (samples were too low to form a valid chi-square approximation).

Hypothesis 9: Sexualisation. Females were found to be more frequently depicted as sexual objects than males in both Malaysian and British advertisements but only statistically significant differences were found in Malaysia $\left(\left(\mathrm{X}^{2}\right)_{\mathrm{UK}}=2.83, \mathrm{df}=1, p>0.05\right.$; $\left.\left(\mathrm{X}^{2}\right)_{\text {Malaysia }}=3.88, \mathrm{df}=1, p<0.05\right)$.

Hypothesis 10: Cross-cultural Comparisons of Male and Female Primary Characters. The qualities of British male primary characters were compared with Malaysian male primary characters and British female primary characters with Malaysian female primary characters in order to identify similarities and differences between countries. and British males, $\mathrm{X}^{2}=15.96, \mathrm{df}=5, p<0.05$. Malaysian male primary characters were more likely to advertise food, and health and beauty products while British male primary characters were more likely to advertise electronics and services.

British female primary characters were found to rely on significantly different types of arguments than Malaysian female primary characters, $\mathrm{X}^{2}=6.65 \mathrm{df}=2, p<0.05$. British females were equally likely to be shown to using either factual and opinion based arguments while Malaysian females were observed to used opinions (61.5\%) more frequently than factual arguments (30.2\%) in advertisements.

Another cross-cultural difference was that humorous advertisements were twice more common in British advertisements than Malaysian advertisements for both males $\left(\mathrm{X}^{2}=10.86, \mathrm{df}=1, p=0.001\right)$ and females $\left(\mathrm{X}^{2}=8.10, \mathrm{df}=1, p<0.005\right)$. As this was seen for both males and females, this would imply that neither gender is particularly associated as being a source of humour and is simply a cultural difference in reliance on humour in advertising.

There were no significant differences found between the portrayal of British men with Malaysian men and British women with Malaysian women in the remaining categories.

\section{Discussion}

Similar to prior studies (Furnham \& Bitar, 1993; Furnham \& Mak, 1999; Bresnahan et al., 2001; Uray \& Burnaz, 2003), female primary characters tended to be used for health and beauty products more than males in both countries; they also showed similar distributions for types of products advertised. On the other hand, significant differences were found for male primary characters across the two countries. Malaysian male primary characters were more likely to promote food, household and body products than their British counterparts who focused on services and electronics. This may imply cultural differences regarding the importance of various goods and services. For example, Malaysians may be slightly more family oriented and invested in self-enhancing goods than the British who may be more interested in convenience goods such as technological devices and financial services. Furthermore, it may also be a reflection of audience demographics. For instance, the collectivist nature of Asian cultures would sug- 
gest that television watching may be a more family oriented activity than in individualistic cultures such as the UK and therefore, Malaysian advertisers would seek to market more family oriented goods during prime-time television slots.

Surprisingly, there were no significant gender differences in location of primary characters in both countries with women being equally likely to be shown at home or outside. Although an earlier study had found a lack of gender differences in Britain (Furnham \& Mak, 1999), advertising in more traditional countries generally tended to depict women in familial and home settings (Bretl \& Cantor, 1988; Gilly, 1988; Furnham \& Bitar, 1993; Uray \& Burnaz, 2003). These results may suggest a global change in attitudes regarding women's place in society, i.e. no longer confined to the stereotypical role of a homemaker. However, male primary characters from both countries were still depicted outside the home in a majority of the commercials despite the closing gap in gender differences.

However, it should be noted that women were still far more likely to be portrayed as non-professional individuals, i.e. without occupations, in both the UK (89.3\%) and Malaysia (85.0\%) in comparison to males who were portrayed as professionals or non-professionals almost equally often. Furthermore, the lack of significant difference between the UK and Malaysia for role portrayals of both genders would suggest that sexism still exists in terms of "appropriate" occupational roles for men and women in spite of progresses in gender equality laws. Therefore, it would appear as though that the media are still perpetuating the stereotype that the majority women tend to be unemployed akin to previous studies (Gilly, 1988; Bresnahan et al., 2001; Uray \& Burnaz, 2003; Kim \& Lowry, 2005; Furnham \& Paltzer, 2010) despite being shown in more recreational settings. This potentially highlights how the contributions of women in the workplace have yet to be fully acknowledged by the media in both a country with longstanding campaigns towards gender equality and a country entrenched in patriarchal ideals. Tan et al.'s (2002) study focusing primarily on occupational role portrayal in Singaporean and Malaysian TV advertising had suggested that the levels of sex stereotyping in Malaysia may have had negative impacts on its economy as a large proportion of the population would be prompted into pursuing non-occupational roles such as homemakers. However, the seemingly negligible long-term effects of advertising on attitudes (Eisend, 2010) would imply that this is due to the society failing to reach a balanced perception of both genders, which is reflected in rather than being caused by the media.

In addition to this, both UK and Malaysian female primary characters were more likely to be depicted as users $(90.4 \%$ and $83.5 \%)$ of a product rather than authorities. While this follows the general trend of previous studies (Furnham \& Mak, 1999; Uray \& Burnaz, 2003; Furnham \& Paltzer, 2010), this study had found to the contrary that male primary characters were also more likely to be shown as users instead of authorities in both countries. It had been initially suggested by prior researchers that being an authority placed the person at a high-credibility or expert status; with the stereotypical associations being that women were of low-credibility while men had high-credibility. 
However, Bretl and Cantor (1988) had noted early on that males were becoming more commonly depicted as users since the original studies. Evidence for the male shift from authority figures to user figures has been found mainly in studies performed in the last decade (Furnham \& Farragher, 2000). Therefore, this could be a sign that the perceptions of users and authorities have changed over time.

Significant gender differences for types of arguments used were only found in UK advertisements while both male and female Malaysian primary characters relied heavily on opinion based arguments. British male primary characters were more likely to present an opinion-based rather than a factual argument; female primary characters were equally likely to present either argument. Comparisons with prior studies performed in the US (Bretl \& Cantor, 1988; Manstead \& Mcculloch, 1981; Furnham \& Skae, 2015) would indicate that there has possibly been a gradual increase in the use of opinion based arguments by men since McArthur and Resko (1975). Gilly (1988) noted that Australian advertisements, which were considered far less stereotypical, tended towards opinion-based arguments as well. Therefore, there might have been a progression from males being associated with factual arguments to gender neutrality in Westernised countries for both these sub-categories. On the other hand, Malaysian female primary characters were significantly more likely to give opinions in comparison to UK females who used both types of arguments equally. This raises the question of whether opinions are generally more important in a traditional culture due to the focus on social networks and hierarchies, i.e. approval of others trumping personal interpretation of facts given. However, due to the contradicting evidence found in previous studies regarding the choice of arguments across countries, it is difficult to discern if this change is consistent over time and across cultures or is a consequence of sampling techniques.

The lack of significant differences within and between cultures for type of rewards utilized by the primary character would suggest that expectations of men and women have been levelling out over time. For example, there appears to be an increase in the use of self-enhancement rewards by male primary characters in comparison to previous studies. However, there has been conflicting evidence from a number of studies regarding the types of reward thereby complicating the predictive quality of this category (Furnham \& Mak, 1999; Furnham \& Paltzer, 2010).

Sexualisation was not particularly prominent in both countries although females were portrayed more frequently as objects of sexual attraction than men in Malaysian commercials. Although females were also more likely to be sexualised in British commercials, men were occasionally used as models as well. There is a stark difference with Malaysia wherein no men were portrayed as sexual object. This could possibly be due to males being perceived as being serious, dominant individuals while women viewed as being more passive and "decorative".

In regard to temperament, the only significant difference found was between the presence of frustration in Malaysian male and female primary characters; with women being depicted as frustrated more frequently as predicted by the hypothesis. Furthermore, the findings support the hypothesis that there would be no gender differences 
found for frustration in British characters. The results would confirm the notion that women in countries typically more prone to gender stereotyping are perceived as being more helpless and emotionally volatile when faced with challenging situations.

Humour was observed to be used more frequently in British advertisements than Malaysian advertisements although there was no significant gender portrayal differences found within each country. The lack of significant differences in distribution was sustained even when the humorous advertisements were further sorted in relation to professional and non-professional roles. This would contradict the suggestion that role reversals (non-professional male and professional female primary characters) mainly occur in humorous circumstances (Furnham \& Skae, 2015). It is more likely that advertisers prefer to use humour in more casual situations regardless of gender.

The lack of significant gender differences in about half of the categories investigated would lead one to conclude that the gender gap in portrayals has been decreasing over time. As the findings show a more equal distribution for women than men within a category, e.g. location and arguments, there is a possibility that it is more acceptable for women to possess traditionally masculine traits than for men to possess effeminate traits. Aside from that, the lack of significant differences for a majority of the crosscountry comparisons would suggest that the perceptions of gender roles in the UK and Malaysia are rather similar despite the disparity between the cultures politically and religiously. Although it was initially hypothesized that this may be due to increased Westernization globally, the occurrence of gender stereotyping within both countries would lead to the conclusion that sexism is still persistent regarding certain issues even decades after the original studies.

Like all others this study had limitations, the most important of which was the sample. Although we had a relatively large sample of television advertisements compared to other studies in this area, it was inevitable limited both in number and the channels sampled. Inevitably the larger the sample the more representative the results. Further this data was collected a few years ago and trends may have changed.

\section{Conclusion}

Future research could concentrate on additional content categories as well as advertisements played at different times of day. More importantly as young people watch television less and less, it would be interesting to content analysing advertisements in the new social media to see if the trends continue. Further, given the growth of many Asian economies, it is important to see how economic growth and development have an impact on advertisements over time.

\section{References}

Bresnahan, M. J., Inoue, Y., Liu, W. Y., \& Nishida, T. (2001). Changing Gender Roles in Prime-Time Commercials in Malaysia, Japan, Taiwan and the United States. Sex Roles, 45, 117-131. http://dx.doi.org/10.1023/A:1013068519583

Bretl, D. J., \& Cantor, J. (1988). The Portrayal of Men and Women in U.S. Television Commer- 
cials: A Recent Content Analysis and Trends over 15 Years. Sex Roles, 18, 595-609. http://dx.doi.org/10.1007/BF00287963

Caballero, M. J., Lumpkin, J., \& Madden, J. (1989). Using Physical Attractiveness as an Advertising Tool: An Empirical Test of the Attraction Phenomenon. Journal of Advertising Research, 29, 16-21.

Cagli, U., \& Durukan, L. (1989). Sex Role Portrayals in Turkish Television Advertising: Some Preliminary Findings. METU Studies in Development, 16, 153-175.

Cooper-Chen, A. (1995). The Second Giant: Portrayals of Women in Japanese Advertising. Association for Education in Journalism and Mass Communication Annual Convention (pp. 65-84). Washington DC: AEJMC.

Eisend, M. (2010). A Meta-Analysis of Gender Roles in Advertising. Journal of the Academy of Marketing Science, 38, 418-440. http://dx.doi.org/10.1007/s11747-009-0181-x

Furnham, A., \& Bitar, N. (1993). The Stereotyped Portrayal of Men and Women in British Television Advertisements. Sex Roles, 29, 297-310. http://dx.doi.org/10.1007/BF00289940

Furnham, A., \& Farragher, E. (2000). A Cross-Cultural Content-Analysis of Sex-Role Stereotyping in Television Advertisements: A Comparison between Great Britain and New Zealand. Journal of Broadcasting and Electronic Media, 44, 415-436. http://dx.doi.org/10.1207/s15506878jobem4403_5

Furnham, A., \& Lay, A. (2017). The Universality of the Portrayal of Gender in Television Advertisements: A Review of the Studies this Millennium. Manuscript under review.

Furnham, A., \& Li, J. (2008). Gender Portrayal in Food and Beverage Advertisements in Hong Kong. Young Consumers, 9, 297-307. http://dx.doi.org/10.1108/17473610810920506

Furnham, A., \& Mak, T. (1999). Sex-Role Stereotyping in Television Commercials: A Review and Comparison of Fourteen Studies Done on Five Continents over 25 Years. Sex Roles, 41, 413437. http://dx.doi.org/10.1023/A:1018826900972

Furnham, A., \& Paltzer, S. (2010). The Portrayal of Men and Women in Television Advertisements: An Updated Review of 30 Studies Published Since 2000. Scandinavian Journal of Psychology, 51, 216-236. http://dx.doi.org/10.1111/j.1467-9450.2009.00772.x

Furnham, A., \& Skae, E. (2015). Changes in the Stereotypical Portrayal of Men and Women in British Television Advertisements. European Psychologist, 2, 44-51. http://dx.doi.org/10.1027/1016-9040.2.1.44

Furnham, A., Gunter, B., \& Walsh, D., (1998). Effects of Programme Context of Memory of Humorous Television Commercials. Applied Cognitive Psychology, 12, 555-567. http://dx.doi.org/10.1002/(SICI)1099-0720(1998120)12:6<555::AID-ACP537>3.0.CO;2-X

Gilly, M. C. (1988). Gender Roles in Advertising: A Comparison of Television Advertisements in Australia, Mexico, and the United States. Journal of Marketing, 52, 75-85. http://dx.doi.org/10.2307/1251266

Hamid, B. D. H. A., Yasin, M. S. M., Bakar, K. A., Chee, K. Y., \& Jaludin, A. (2008). Linguistic Sexism and Gender Role Stereotyping in Malaysian English Language Textbooks. Online Journal of Language Studies, 8, 45-78.

Ingrassia, M. (1994). Going One Step Ogle the Line? Newsweek, 30, 66.

Kay, A., \& Furnham, A. (2013). Age and Sex Stereotypes in British Television Advertising. Psychology of Popular Media Culture, 2, 171-186. http://dx.doi.org/10.1037/a0033083

Kim, K., \& Lowry, D. T. (2005). Television Commercials as a Lagging Social Indicator: Gender Role Stereotypes in Korean Television Advertising. Sex Roles, 53, 901-910. http://dx.doi.org/10.1007/s11199-005-8307-1 
Knoll, S., Eisend, M., \& Steinhagen, J. (2011). Gender Roles in Advertising. International Journal of Advertising, 30, 867-888. http://dx.doi.org/10.2501/IJA-30-5-867-888

Lin, C. A. (1998). Uses of Sex Appeals in Prime-Time Television Commercials. Sex Roles, 38, 461-475. http://dx.doi.org/10.1023/A:1018714006829

Manstead, A. S. R., \& McCulloch, C. (1981). Sex-Role Stereotyping in British Television Advertisements. British Journal of Social Psychology, 20, 171-180. http://dx.doi.org/10.1111/j.2044-8309.1981.tb00529.x

McArthur, L. Z., \& Resko, B. G. (1975). The Portrayal of Men and Women in American Television Commercials. Journal of Social Psychology, 97, 209-220. http://dx.doi.org/10.1080/00224545.1975.9923340

Morrison, M. M., \& Shaffer, D. R. (2003). Gender-Role Congruence and Self-Referencing as Determinants of Advertising Effectiveness. Sex Roles, 49, 265-275.

http://dx.doi.org/10.1023/A:1024604424224

Schneider, K. C., \& Schneider, S. B. (1979). Trends in Sex Roles in Television Commercials. Journal of Marketing, 43, 79-84. http://dx.doi.org/10.2307/1250149

Seligman, M. E. P. (1975). Helplessness: On Depression, Development and Death. San Francisco, CA: Freeman.

Shaw, P., Eisend, M., \& Tan, Y. (2014). Gender-Role Advertising in International Advertising. In H. Cheng (Ed.), The Handbook of International Advertising Research. Hoboken, NJ: WileyBlackwell. http://dx.doi.org/10.1002/9781118378465.ch15

Sullivan, G. L., \& O’Connor, P. J. (1988). Women's Role Portrayals in Magazine Advertising: 1958-1983. Sex Roles, 18, 181-188. http://dx.doi.org/10.1007/BF00287788

Tan, T. T. W., Ling, L. B., \& Theng, E. P. C. (2002). Gender-Role Portrayals in Malaysian and Singaporean Television Commercials: An International Advertising Perspective. Journal of Business Research, 55, 853-861. http://dx.doi.org/10.1016/S0148-2963(00)00225-3

Uray, N., \& Burnaz, S. (2003). An Analysis of the Portrayal of Gender Roles in Turkish Television Advertisements. Sex Roles, 48, 77-87. http://dx.doi.org/10.1023/A:1022348813469

\section{Submit or recommend next manuscript to SCIRP and we will provide best service for you:}

Accepting pre-submission inquiries through Email, Facebook, LinkedIn, Twitter, etc.

A wide selection of journals (inclusive of 9 subjects, more than 200 journals)

Providing 24-hour high-quality service

User-friendly online submission system

Fair and swift peer-review system

Efficient typesetting and proofreading procedure

Display of the result of downloads and visits, as well as the number of cited articles

Maximum dissemination of your research work

Submit your manuscript at: http://papersubmission.scirp.org/

Or contact psych@scirp.org 